\title{
Factors influencing the quality of undergraduate clinical restorative dentistry in the UK and ROI: the views of heads of units
}

IN BRIEF

- A comprehensive review of the barriers and facilitators to the provision of undergraduate clinical restorative dentistry in the UK and ROI.

- Provides a clear picture of the current status of the teaching and learning of undergraduate restorative dentistry in the UK and ROI.

Will help to inform policy makers and stakeholders.

\author{
N. Martin, ${ }^{1}$ A. Fairclough, ${ }^{2}$ M. Smith ${ }^{3}$ and L. Ellis ${ }^{4}$
}

In the light of concerns regarding expanded student intakes and reported workforce difficulties, a 2008 survey of heads of departments of restorative dentistry in UK and ROI dental schools sought to clarify the current situation with regard to: workforce configuration; barriers and facilitators of quality undergraduate clinical restorative dentistry; and, implications of the above for programme delivery. The response rate was 100\% for the workforce statistics and 65\% for the remainder of the survey. Findings were largely consistent across the 14 schools. Workforces were increasingly part-time with a shortage of full-time academics. While resources had generally expanded to meet increased student numbers and outreach teaching had augmented clinical learning, difficulties in recruiting patients and communicating with a fragmented workforce were risking the quality of undergraduate curricula. Issues to be addressed include a pervading sense of teaching being undervalued and staffing being sub-optimal.

\section{INTRODUCTION}

While the General Dental Council ${ }^{1}$ and Quality Assurance Agency for Higher Education $^{2}$ specify and quality assure undergraduate dental programmes, it falls to dental schools to design curricula that fulfil these requirements. Anecdotal evidence suggests that departments of restorative dentistry are recently experiencing greater difficulties in providing high quality clinical learning experiences partly because of the burden of quality assurance. Further, the literature suggests factors impinging on quality education in clinical dentistry include competing demands, difficulties recruiting and retaining staff, and increased student numbers. These factors are next considered in turn.

In the face of competing pressures from service provision, teaching and research clinical academics prefer to devote more

:2Academic Unit of Restorative Dentistry, ${ }^{3}$ Dental Public Health, School of Clinical Dentistry, The University of Sheffield, School of Clinical Dentistry, Claremont Crescent, Sheffield, S10 2TA; ${ }^{4}$ School of Health Sciences, University of Derby, Kedleston Road, Derby, DE22 1GB ${ }^{*}$ Correspondence to: Dr Nicolas Martin Email:n.martin@sheffield.ac.uk

\section{Refereed Paper}

Accepted 9 April 2010

DOI: 10.1038/sj.bdj.2010.498

${ }^{\circledR}$ British Dental Journal 2010; 208: 527-531 time to research and less on teaching though teaching was an attractor to the career. ${ }^{3}$ Despite establishments' revenues from teaching generally exceeding those from research, Pee et al. ${ }^{4}$ assert the need to redress the balance of the recognition in favour of teaching.

An international perspective on staffing found that recruitment, development and retention of dental academic staff with skills and interests in research, education and clinical dental treatment delivery are major challenges for all dental schools. Dental academia is perceived to lack the attractions and rewards of private practice and dental schools may inadvertently present barriers to potential entrants, eg in the UK, structured academic career pathways, incorporating recognised clinical training programmes, have been created but are considered unattractively protracted and cumbersome. ${ }^{5-7}$ The age profile of UK dental educators, most being over 50 , is a concern. ${ }^{8}$

The decade to 2005 saw a $42 \%$ increase in dental student numbers while over a similar period the number of full time equivalent dental clinical academics was said to fall by $7 \%$ or more. ${ }^{9,10}$

In the light of these concerns evidence was sought to clarify the current situation. This paper reports the findings of a survey designed to capture the perceptions and experiences of senior academics on the factors affecting quality in undergraduate clinical restorative dentistry.

\section{MATERIALS AND METHODS}

All dental schools in the UK and ROI were sent a survey pack in June 2008 containing a cover letter, participant information sheet, consent form and the questionnaire for the Head of Department (HoD) of conservative dentistry or equivalent. A reminder follow-up letter was sent four weeks later. Soon afterwards, an email enquiry was made to all non-respondent HoDs requesting information about their departmental workforce profile. Ethical approval was obtained before commencement of the study.

The questionnaire was designed to answer the following questions:

(a) What is the configuration for the workforce?

(b) What are the barriers to and facilitators of quality undergraduate clinical restorative dentistry?

(c) What are the implications of the above for programme delivery?

To improve comparability of responses the terminology to be used for staff roles was specified (Table 1). 


\begin{tabular}{|c|c|}
\hline Role title & Descriptor \\
\hline Head of Department & $\begin{array}{l}\text { Head of a department of conservative/restorative dentistry with leadership and management for the department and the discipline's } \\
\text { undergraduate curriculum }\end{array}$ \\
\hline Clinical Dental Educator & Individual with a role in undergraduate clinical teaching in conservative/restorative dentistry - irrespective of seniority status \\
\hline Senior Clinical Staff & Clinical professors, senior clinical lecturers, senior clinical teachers, consultants, associate specialist and head of unit \\
\hline Non-Senior Clinical Staff & $\begin{array}{l}\text { Clinical lecturers, clinical teachers, clinical fellows, clinical assistants, clinical tutors, specialist registrars (Honorary and NHS), staff } \\
\text { grades and general dental practitioners }\end{array}$ \\
\hline Full time staff & Full time commitment to the university or hospital with clear clinical teaching responsibilities in clinical restorative dentistry \\
\hline Part time staff & With equal responsibilities as full-time staff but with a commitment of less than full-time \\
\hline
\end{tabular}

\section{RESULTS}

\section{Response rates}

Eleven of the 17 HoDs returned completed questionnaires: a response rate of 65\%. With the addition of emailed responses from all remaining HoDs the response rate for the workforce profile sections was 100\%. All respondents had at least one year's experience as HoD and worked in the sub-specialties of prosthodontics (fixed and removable), conservative dentistry and endodontics.

Respondents described a range of factors said to contribute to quality undergraduate dental education and training. The results are presented factor by factor and illustrated by verbatim extracts from respondents. Centres were allocated letters A-Q for anonymised reporting of findings.

1. Composition of the workforce

2. Facilities and resources

3. Student clinical experience

4. Number of students

5. Patient availability and profile

6. Multiple competing demands

7. Academic leadership and succession planning.

\section{Composition of the workforce}

Typically a department consisted of 36 staff (SD 14), seven of them senior staff and ten full-time, SDs 2 and 5 respectively (Figs 1-2). Sixty-four percent of responding HoDs reported a noticeable change over the last five years with fewer appointments, more unfilled posts and most of the staff now being part-time rather than full-time. Increased reliance on part-time general dental practitioners and clinical teachers resulted in the course administration burden being borne by the smaller core of full-time staff putting pressure on their time for teaching and research. It

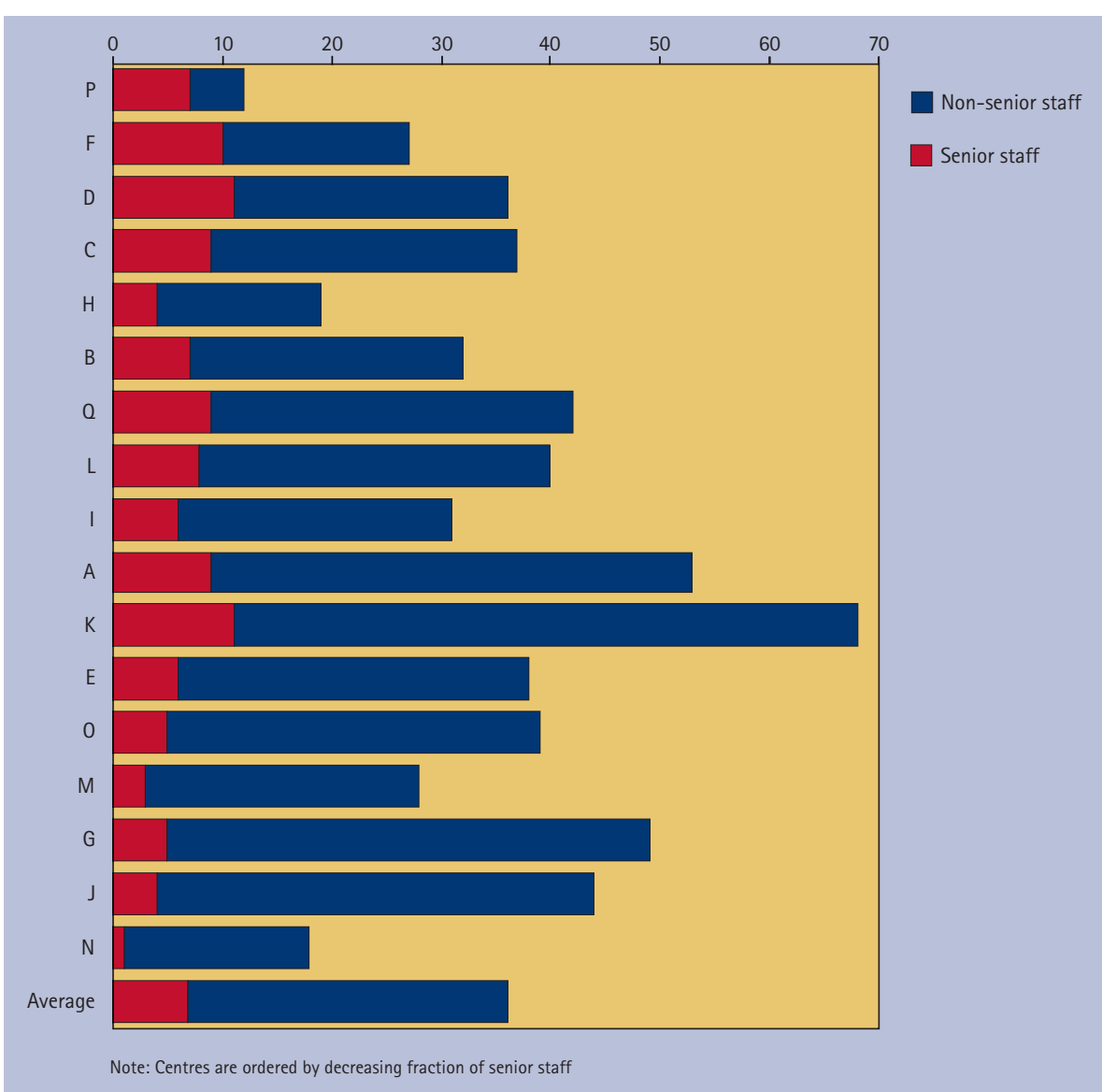

Fig. 1 Number of clinical senior and non-senior staff for each centre

also increased difficulties in maintaining a common approach to teaching, collegiality and providing absence cover.

'The role of senior clinical academics has changed: less scheduled floor walking and more of an overseeing, strategic responsibility for specific areas of curriculum content.' (Centre 0)

'One-day a week teachers, do not know what is being taught in the phantom head room.' (Centre G)

'There is a need to set a minimum sessional commitment (5-6 sessions) for part-time staff with some administrative responsibility.' (Centre $\mathrm{K}$ )

Asked for the 'best staff make-up' for 'high quality clinical teaching' there was a consensus for a strong core of full-time staff (typically 40-60\%) with input from good general dental practitioners (GDPs) preferably qualified in teaching.

\section{Facilities and resources}

Clinical sessions were typically resourced by one clinician and one nurse to each seven students $(\mathrm{n}=11$; SDs $=1.0,3.7)$. Nurse turnover was rated moderate by most centres $(n=8)$, while 2 rated this 
high and 2, low. Integrating nurses into dental teams was the main factor ensuring nurse retention with other factors mentioned including lower pay than in dental practice, attractive working conditions, security of employment and the varied, rewarding work. The consensus was that universities did not appreciate restorative dentistry's requirement for a high clinical staff:student ratio and the demands teaching made of staff.

The number and distribution across years of clinical teaching sessions varied between centres (Fig. 3). These sessions were in addition to those dedicated to phantom head sessions, pre-clinical skills laboratory, tutorials, lectures, etc. Clinical teaching occurs predominantly in polyclinics with $45 \%$ of centres (C, E, H, K, O) using specialty clinics eg in complete dentures or endodontics.

The total student intake for the ten centres reporting complete data sets rose from 666 in 2004, peaked at 762 in 2005 and was anticipated to remain constant at the 2008 figure, 688, until 2013. The numbers of dental chairs and staff employed in clinical dentistry had increased in proportion to student enrolments.

Table 2 compares the number of clinical students per available departmental chair across the centres, ie ignoring any outreach chairs. These data indicate a mean demand on clinical space of four students per chair, range 1-6.

\section{Student clinical experience}

Outreach settings (working in locations distant from the centre) were employed by $55 \%$ of centres to increase undergraduates' experience (C, H, I, K, L, O). Some 64\% of centres used the strategy of paired working (where students from the same year nurse for one another) in the dental hospitals and/or outreach environments. Pairing was generally viewed as a pragmatic strategy to manage large student numbers and provide the necessary clinical exposure. It does not, however, contribute to an improvement of the quality of clinical education in restorative dentistry.

'The number of clinical contact sessions has reduced because students spend half of their time nursing.' (Centre C)

'Could not operate without paired teaching.' (Centre J)

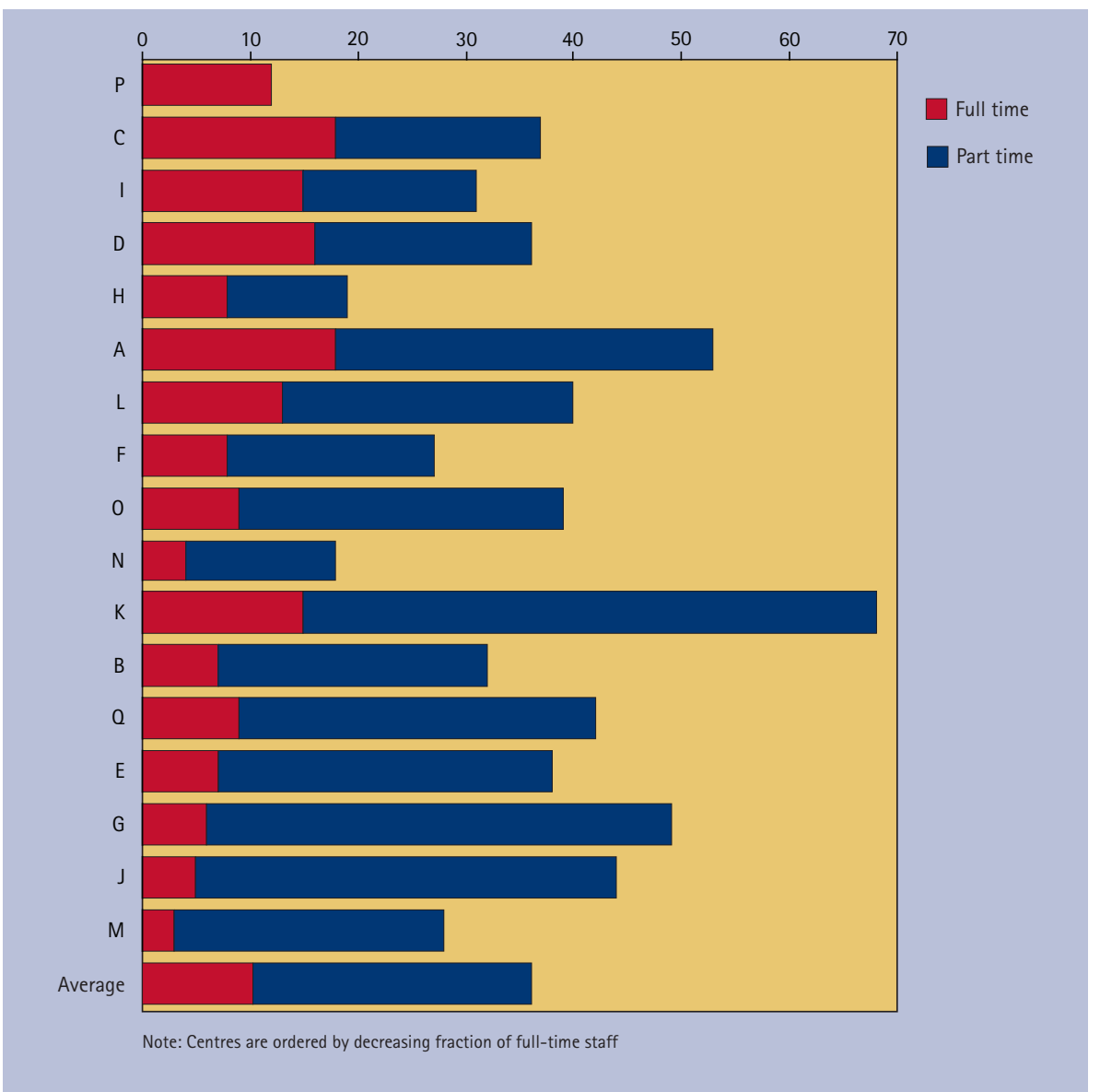

Fig. 2 Numbers of full-time and part-time staff at each centre

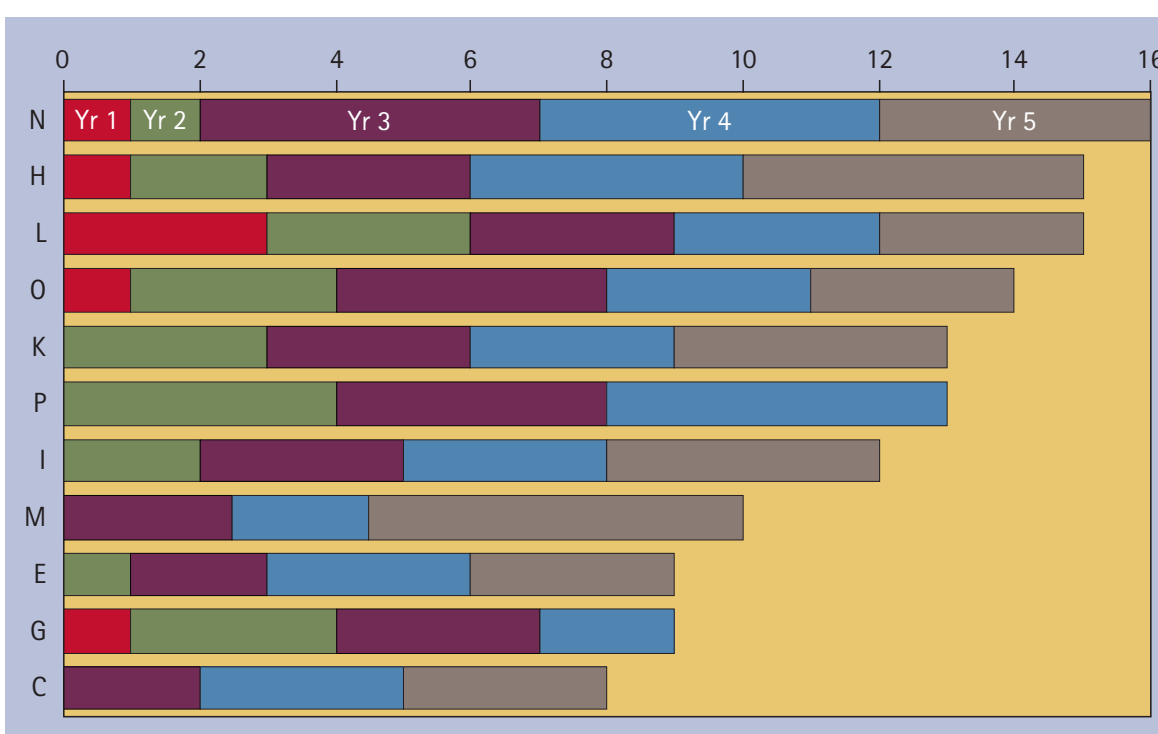

Note: Centres arranged in decreasing total number of sessions

Fig. 3 Number of timetabled clinical sessions ( $1 / 2$ day $=3$ hours) per week for each student in the department of conservative/restorative dentistry in each year of the course

'Paired teaching dilutes teaching enormously' and '[paired teaching] could be avoided by employing more staff and nurses and with greater chair availability.' (Centre G)

Students' clinical experience had changed over the last five years generally with a reduction in clinical time, sometimes associated with paired working, but often a broader experience with more complex cases. Comments included 'more toothwear cases and rotary endo', 'a shift from amalgam to composite', 'increased patient demand for 


\begin{tabular}{|c|c|c|c|c|c|c|c|c|c|c|c|}
\hline Centre & c & $\mathrm{E}$ & G & $\mathrm{H}$ & I & $\mathrm{K}$ & $\mathrm{L}$ & $M$ & $\mathrm{~N}$ & 0 & $P$ \\
\hline Number of registered students & 319 & 200 & 860 & 480 & 361 & 429 & 359 & 208 & 197 & 371 & 32 \\
\hline Number of students in clinical years & 181 & 160 & 860 & 480 & 297 & 338 & 299 & 110 & 197 & 289 & NA \\
\hline Number of dental chairs available for students & 140 & - & 170 & 100 & 90 & 91 & 50 & 24 & 34 & 116 & 32 \\
\hline Clinical students per chair & 1.3 & - & 5.1 & 4.8 & 3.3 & 3.7 & 6.0 & 4.6 & 5.8 & 2.5 & [1.0] \\
\hline
\end{tabular}

aesthetic dentistry' and that with the addition of outreach experiences students were better prepared on qualification.

\section{Patient availability and profile}

A universal difficulty, which had deepened over recent years in $80 \%$ of centres, was ensuring an adequate supply of appropriate patients for undergraduate treatment. Patients requiring simple/intermediate restorative treatment or complete dentures were the most difficult to recruit. Those with high caries rates and extensive periodontal disease were found unreliable and non-compliant making them unsuitable for students. A compounding issue was the competition for patients from other educational programmes, especially the dental hygiene and therapy courses mentioned by eight centres. While some considered outreach settings invaluable in increasing students' clinical experience with suitable patients, these settings were also viewed as more accessible competitors for patients. The dental school being in an area where dental pathology was scarce or with limited car parking were factors here.

The social profile of patients attending dental hospitals for undergraduate treatment has altered over recent years. A policy of discharging longstanding compliant patients no longer needing treatment required by students may have had an effect and there was limited educational value in patients who simply require reviewing.

Strategies aimed at ensuring an appropriate profile of patients for student treatment included: advertisement, via clinics, GDP referrals, staff/students/family/friends recommendations and targeted recruitment through various National Health Service (NHS) and university health services. GDPs' referrals tended to involve inappropriately complex treatment needs. An unintended consequence of active recruitment campaigns offering free treatment was an increase in poorly motivated patients often with significant dental neglect and seeking a 'quick fix'. They rapidly became frustrated and impatient with slow student treatment and are less compliant, resulting in cancellations or failure to attend.

Identifying patient suitability predominantly involved screening and assessment clinics. While expensive and time consuming these were effective and essential for populating undergraduate waiting lists.

\section{Multiple competing demands}

A wide range of 'hindrances to the delivery of quality teaching and learning' were identified and ranked by HoDs when their rankings probably reflected local factors. However, commonalities centred around time pressures from competing activities and a lack of full-time staff available to offer support.

Perhaps predictably, administration, meetings, authorising absence cover and the management of staff were unattractive time-consuming aspects of workload which had increased. The universally noted increase in administrative burden was attributed to an over emphasis of quality assurance's demands to document everything. Research was considered a core activity not deemed a competing pressure. Indeed, research would gain from any reduction in administrative duties.

Opportunities for the reflection required to maintain standards and innovate were being squeezed out. Other hindrances were lack of time to develop teaching, the additional difficulties arising from a large part-time complement and NHS targets unsupportive of learners' needs. Any shortfall in physical resources exacerbated these problems.

Notably, three respondents indicated that they had considered leaving clinical academic dentistry for alternative employment citing the above demands and a frustrating lack of autonomy.

\section{Academic leadership and succession planning}

Seeing their students mature into competent clinicians and qualify was especially gratifying for HoDs. They also found leadership and management rewarding. Succession planning and career development were problematic in light of the aforementioned workforce problems. Compared to the NHS, promotion criteria within universities were considered too inflexible and inappropriate for dentistry.

Recasting the role of the senior clinical academic at a more strategic level with less clinical teaching was suggested. However, other respondents valued the patient care aspects of their work and considered it important to the profession:

Despite all the aforementioned difficulties and thanks to the commitment of staff...

'On qualification students will have demonstrated competence in all core restorative skills...[and] their ability to integrate restorative care for adult patients... Compared to 15 years ago clinical experience is less but is undertaken in a more structured and supportive clinical environment.' (Centre K)

\section{DISCUSSION}

This survey presents the views of the Heads of Departments of restorative dentistry with responsibility for the delivery of teaching and learning of restorative dentistry in undergraduate dental schools of the UK and ROI. The response rates, combined with the extensive commonality of themes among respondents, suggest that the findings detailed in this report can be 
considered an accurate portrayal of the current state of undergraduate clinical teaching in the UK and ROI at the time of this survey.

Since the inception of the NHS, the dental profession in the UK has been dominated by NHS policy changes and associated alterations to contracts and remuneration. ${ }^{11,12}$ Recent studies of the provision of dental practice and education together highlight shortfalls in workforce composition, recruitment, morale and retention together with a growing discontent among a dental profession that remains committed to training their next generation through high quality undergraduate education. ${ }^{13-15}$

Perhaps unsurprisingly, therefore, this study concurs with some of the findings of these previous studies in identifying factors impinging negatively on undergraduate training: increasing reliance on part-time staff and the inherent difficulties this brings for communication and collegiality; and, increased competition between schools in recruiting from a diminishing pool of academically qualified staff. The first of these is not noted in the literature. While the NHS is addressing workforce concerns, for example through the 'keeping in touch scheme', their impact will only be in the longer term. ${ }^{11}$

The increasingly part-time staffing and greater student numbers were thought to increasingly fragment patient care and students' learning. Students' learning was threatened by reduced clinical time and the increased difficulties in securing sufficient appropriate patients. These findings may resonate with Holt's ${ }^{16}$ suggestion that the profession has shown a remarkable lack of imagination and vision in organising itself to provide the best kind of care for patients.

Nevertheless, the commitment of staff ensures students qualify despite these obstacles. It is perhaps ironic that several centres have embraced initiatives such as problem based learning as the foundation for students' lifelong learning while themselves having limited access to continuing professional education on account of being part-time staff. An increase in morale and easier future recruitment could result from teaching being accorded greater status when compared with research.

In view of these findings the following recommendations are made:

- An appropriate workforce balance is vital for ensuring a quality dental education. Consideration should therefore be given to the knowledge and skill mix of the workforce with particular reference to the level of staff and the appropriate use of part time staff. Failure to achieve a significant investment in future staffing risks the quality of teaching in restorative dentistry

- There is a need for universities to recognise that clinical teaching is a core element of a dental academic's role, that the provision of quality teaching is staff resource intensive

- There is a need for teaching to be at least on a par with research, especially when considering career development, recognition and promotion

- Centres need to identify innovative strategies for either attracting sufficient appropriate patients to meet the students' learning needs or provide alternative learning opportunities either with patients or in advanced simulation laboratories

- Centres need to reflect on the link between existing working practices (especially the administrative burden), the quality of their provision and patient care.

In conclusion, this 2008 snapshot survey of senior restorative dentistry HoDs found a remarkably consistent picture across the UK and ROI. The workforce was increasingly part-time with a shortage of core full-time academics carrying an increasing administrative burden. Their age profile was skewed towards retirement. While, in many cases, resources had expanded to meet increases in student numbers and outreach teaching had augmented learning opportunities, difficulties in recruiting suitable patients and in maintaining a coherent approach with a fragmented workforce were threatening the quality of undergraduate curricula. A pervading sense of teaching being undervalued and staffing levels being sub-optimal are issues to be addressed.

The authors wish to acknowledge and thank all those who contributed to this survey and painstakingly answered and returned the questionnaires. They also acknowledge and thank the British Association of Teachers of Conservative Dentistry and The University of Sheffield for their financial support.

1. General Dental Council. The first five years, 3rd ed. (Interim) Framework for undergraduate dental education. London: GDC, 2008. Available from www.gdc-uk.org.

2. The Quality Assurance Agency for Higher Education. Subject Benchmark Statements: Dentistry. Gloucester: QAA 2002. Available from www.qaa.ac.uk.

3. Goldacre M, Lee P, Stear S, Sidebottom E, Richards R. Views of academic dentists about careers in academic dentistry in the United Kingdom. Br Dent J 2000; 188: 154-159.

4. Pee B, Woodman T, Davenport E S. Developing teaching and learning innovations in dental training: the example of the Progress File Learning System. Br Dent J 2003; 195: 463-466.

5. Richards R. Clinical academic careers - report of an independent task force. London: Committee of Vice Chancellors and Principals, 2007.

6. Walport Report. Academic Careers Sub-Committee of Modernising Medical Careers. Medically and dentally qualified staff: Recommendations for training the researchers and educators of the future. UK Clinical Research Collaboration, 2005.

7. Corbet E, Akinwade J, Duggal R et al. Staff recruitment, development and global mobility. Eur J Dent Educ 2008; 12: 149-160.

8. Kay E J, O'Brien K D. Academic dentistry - where is everybody? Br Dent J 2006; 200: 73-74.

9. Rushton V E, Horner K. Academic dentistry. J Dent 2008; 36: 472-480.

10. Dental Schools Council. Staffing levels of dental clinical academics and dental clinical teachers in UK dental schools. London: DSC, 2009. Available from www.medschools.ac.uk.

11. Firmstone V R, Bullock A D, Bedward J, Frame J W. Supporting return to dentistry: a national evaluation of the Retaining and Returning Advisory Service. Br Dent J 2007; 203: 413-417.

12. Milsom K M, Threlfall $A$, Pine $K$, Tickle $M$ et al. The introduction of the new dental contract in England - a baseline qualitative assessment (comment). Br Dent J 2008; 204: 281.

13. Sprod A, Boyles J. The workforce of professionals complementary to dentistry in the general dental services: a survey of general dental practices in the South West. Br Dent J 2003; 194: 389-397.

14. Jackson R J, Baird W O, Worthington L S, Robinson $P G$. A survey to investigate shortfalls in the dental care professional (DCP) workforce in South Yorkshire in 2004. Br Dent J 2003: 194: 389-397.

15. Gilmour J, Stewardson D A. Morale of vocational dental practitioners in the United Kingdom. Br Dent J 2008; 204: E18, 620-621.

16. Holt V P. The need for leadership and vision in dentistry. A personal view. Prim Dental Care 2008; 15: $113-119$. 